\section{On the Internal Fluidity of the Earth}

THE question of the solidification of the crust of the earth from the fluid interior nucleus, as referred to by $\mathrm{Mr}$. Mathieu Williams, in NATURE, vol. xv. p. 5, is one which has been long since fully discussed in my papers in the Philosophical Transactions, the Atlantis, vol. i., and in a paper of which an abstract appears in the Report of the British Association for 1856 . As far as I am aware, no person has controverted my conclusions as to the process of solidification of the earth. The results are, in the main, somewhat similar to those so admirably illustrated and enforced by Mr. Rubert Mallet, and also such as $\mathrm{Mr}$. Williams upholds in this journal.

In articles 6 and 7 of my "Researches in Terrestrial Physics," Part I, this subject is discussed as a problem of fluid equilibrium, and the conclusion is there deduced that the fluid interior mass of the earth must consist of spheroidal strata of equal density, the density of each stratum increasing from the surface to the centre of the nucleus. The mode in which this arrangement of the fluid matter would favour the formation of a solid crust is pointed out. In Part 2 Section III., the probable law of density of these fluid strata is discussed. In Section IV. the shape of these stra:a is investigated, and also that of the inner surface of the shell or crust. It is shown independently of the law of density that the least ellipticity of this inner surface of the crust cannot be less than the ellipticity of its outer surface. A similar result was soon afterwards enunciated by Plana in a paper in the Astronomische Nachrichten. In the same section the theory of a solid nucleus in the earth originally proposed by Poisson, is examined and shown to be incompatible with physical laws.

Owing to the pointed manner in which Sir William Thomson invited discussion in a previous number of NATURE, I ventured to controvert his views as to the rigidity of the earth in a paper inserted at p. 288, vol. v. of this journal. Never at any time have I had even a doubt as to the untenable character of Sir William Thomson's views regarding the solidity of the earth.

In again reiterating this opinion in NATURE, vol. ix. p. 1O3, a reference to my paper was given, in which vol. vii. p. 288 , is misprinted for vol. v. p. 288

In his address at Glasgow Sir William Thomson, while maintaining his opinion as to the earth's solidity, appears to have seen the weakness of some of his former arguments by calling on his hearers (NATURE, vol. xiv. p. 428) to erase whole paragraphs of his paper on the Rigidity of the Earth, in the Fhilo sophical Tiransactions. At the same passage of his address he refers to a hint from Prof. Newcomb, that viscosity might suffice to render nrecession and nutation, the same as if the earth were rigid. "This," he says, "I would not for a moment admit, any more than when it was first put forward by Delaunay." The Comptes Rendus of the Academy of Sciences of Paris for March 6, $18 \mathrm{7r}$, contains a paper in which my priority on this point is clearly established. In NATURE, vol. iii. p. 420, the following statement occurs :-_" Paris Academy of Sciences, March I 3. M. Delaunay read a declaration stating that he acknowledged that Mr. Hennessy had used the same arguments as himself against Mr. Hopkins' theory relative to the fluidity of the interior parts of the earth."

I am willing to believe that Sir William Thomson had neither seen the Conptes Rendus nor the paragraph in NATURE just quoted, but it is to be regretted that a presidential address should contain an erroneous statement on a point of recent scientific history, especialiy when the error could be avoided by a glance at the most widely known sciertific publications.

All through the portion of his address which refers to the earth's structure Sir William Thomson assumes that the views of Mr. Hopkins are established and admitted. A reference to some of the past volumes of this journal alone shows the inadmissibility of such an assumption. At pp. 45 and 182 of vol. iv. and elsewhere Mr. Hopkins' views are distinctly controverted on mechanical, physical, and geological grounds.

It appears that in the discussion on my paper in the Academy of Sciences of Paris, in which some of the most eminent mathematicians and geologists of France took part, not one of them adopted Mr. Hopkins' “Discovery of the earth's solidity." As far as I am aware, this "discovery" is not adopted anywhere on the continent of Europe. I have studied with as much care and attention as I could give to them, the mathematical and physical researches of Mr. Hopkins and Sir William Thomson relative to this subject, and for reasons already partly unfolded in this journal at vol. v. p. 288 and vol. iv. p. 182, I continue to firmly adhere to the almost diametrically opposite conclusions Jong since enunciated in the publications referred to at the outset of this conmunication.

Royal College of Science, Dublin

HENRY HENNESSY

\section{The Age of the Rocks of Charnwood Forest}

I SEE that in Mr. Woodward's "Geology of England and Wales," recently published, the rocks of Charnwood Forest, in Leicestershire, are (with some hesitation) referred to the "Laurentian" series, Prof. Ansted and Dr. Holl being quoted as authorities. The reviewer in the recent number of the Saturday Review adopts the same opinion; at the same time it is proper to add that Mr. Woodward states in another place (p. 31) that the Charnwood Forest rocks " may be of Cambrian age," so that the reader is left to take his choice.

For my part I confess to being at a loss to understand on what grounds these old rocks can be referred to any other than the Cambrian period. The evidence in any case is small, but what there is points to this conclusion.

In the first place it ought to be remembered that the age of these rocks was first indicated by Prof. Sedgwick, whose opinion on such a question should not be disregarded umless on very sub. stantial grounds. Sedgwick's opinion of their age was founded almost entirely on lithological grounds, and no one was better qualified to recognise the representatives of the Welsh Cambrians, though rising up isolated amongst much newer formations in the heart of England. Prof. Jukes, in his description of the geology of Charnwood Forest, appended to Porter's "History," adopted the same view, in which the officers of the Geological Survey, including the present Director-General, who made a personal examination of the forest rocks, cincurred (see "Geology of the Leicestershire Coal Field," Mem. Geol. Survey, I860). I am not aware that they have changed their views owing to what has been since written on the subject.

As regards the determination of the age of these rocks, if it is impossible to prove them to be of Cambrian age, there are very good grounds for concluding they are not of "Laurentian" age, assuming that term to refer to the fundamenral yneiss of the northwest Highlands and Isles of Scotland. These rocks consist, according to the description of Murchison, of coarsely crystalline gneiss, full of granite veins. They are cvery where intensely metamorphosed. Now, this is far from being the case with the Charnwcod Forest rocks. Generaliy they are no nore metamorphosed than are the Cambrian beds of the Longmynd, or of Llanberis. True "gneiss" is very exceptional, and metamorphic action is quite local, and is chiefly confined to one district. Any argument, therefore, drawn from ithological re. semblance to the rocks of the typical district entircly fails; and I cannot admit that the occurrence of rocks (syenite, \&c.) resembling those of the Malvern Hills, is of any force in this riuesion, as it is very far from having been proved that the Malvern Rocks are of Lanrentian age.

As regards evidence founded on organic remains, it is of the most meagre kind, but whatever the obscure markings on the slates of Charnwood may really be, they are certainly not those of eozoon. From whatever side, therefore, the question is viewed, there appears to be no good ground for departing from the view regarding the age of these rocks originally adopted by Sedgwick.

EDWARD HULL

Geological Survey Office, Dublin, November 3

\section{Mind and Matter}

Mr. Spalding in his critique on Maudsiey's "Physiology of Mind" (NATURE, vol. xiv. p. 54I), while admitting that "the dependence of consciousness on nervous organisation, seemed," by the science of nerve physiology, "to be fairiy established," stated that the difficulty of conceiving how consciousness stood related to the material organism, was a difficulty which had not yet been overcome.

Might not this problem be solved somewhat thus:-It is as easy to predicate subjectivity (or susceptibility to consciousness) of one entity called matter, as of another entity called soul or spirit. It is no more difficult to conceive of matter being subjective than of spirit being subjective.

Again, energy accompanies matter in all its forms, and yet 